
A UNITED STATES DEPARTMENT OF POMMERGE PUBLIGATION
Nattonal Bureau of Standaras Library, E-01 Admin. Bldg.

FEB 161970

\section{NBS TECHNICAL NOTE 516}

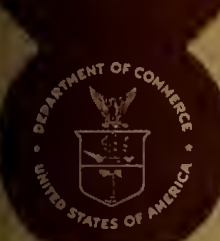

\section{A Selective Roll-to-Roll Printer \\ for Producing Duplicate Microfilm Copies}

\section{D.S. DEPARTMENT OF COMMERCE

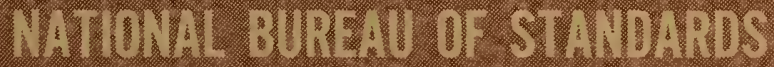




\section{NATIONAL BUREAU OF STANDARDS}

The National Bureau of Standards ' was established by an act of Congress March 3, 1901. Today, in addition to serving as the Nation's central measurement laboratory, the Bureau is a principal focal point in the Federal Government for assuring maximum application of the physical and engineering sciences to the advancement of technology in industry and commerce. To this end the Bureau conducts research and provides central national services in four broad program areas. These are: (1) basic measurements and standards, (2) materials measurements and standards, (3) technological measurements and standards, and (4) transfer of technology.

The Bureau comprises the Institute for Basic Standards, the Institute for Materials Research, the Institute for Applied Technology, the Center for Radiation Research, the Center for Computer Sciences and Technology, and the Office for Information Programs.

THE INSTITUTE FOR BASIC STANDARDS provides the central basis within the United States of a complete and consistent system of physical measurement; coordinates that system with measurement systems of other nations; and furnishes essential services leading to accurate and uniform physical measurements throughout the Nation's scientific community, industry, and commerce. The Institute consists of an Office of Measurement Services and the following technical divisions:

Applied Mathematics-Electricity-Metrology-Mechanics-Heat-Atomic and Molecular Physics-Radio Physics "-Radio Engineering "-Time and Frequency "-Astrophysics "-Cryogenics."

THE INSTITUTE FOR MATERIALS RESEARCH conducts materials research leading to improved methods of measurement standards, and data on the properties of well-characterized materials needed by industry, commerce, educational institutions, and Government; develops, produces, and distributes standard reference materials; relates the physical and chemical properties of materials to their behavior and their interaction with their environments; and provides advisory and research services to other Government agencies. The Institute consists of an Office of Standard Reference Materials and the following divisions:

Analytical Chemistry-Polymers-Metallurgy_Inorganic Materials_-Physical Chemistry. THE INSTITUTE FOR APPLIED TECHNOLOGY provides technical services to promote the use of available technology and to facilitate technological innovation in industry and Government; cooperates with public and private organizations in the development of technological standards, and test methodologies; and provides advisory and research services for Federal, state, and local government agencies. The Institute consists of the following technical divisions and offices:

Engineering Standards-Weights and Measures - Invention and Innovation - Vehicle Systems Research-Product Evaluation-Building Research-Instrument Shops-Measurement Engineering-Electronic Technology-Technical Analysis.

THE CENTER FOR RADIATION RESEARCH engages in research, measurement, and application of radiation to the solution of Bureau mission problems and the problems of other agencies and institutions. The Center consists of the following divisions:

Reactor Radiation-Linac Radiation-Nuclear Radiation-Applied Radiation.

THE CENTER FOR COMPUTER SCIENCES AND TECHNOLOGY conducts research and provides technical services designed to aid Government agencies in the selection, acquisition, and effective use of automatic data processing equipment; and serves as the principal focus for the development of Federal standards for automatic data processing equipment, techniques, and computer languages. The Center consists of the following offices and divisions:

Information Processing Standards-Computer Information - Computer Services - Systems Development-Information Processing Technology.

THE OFFICE FOR INFORMATION PROGRAMS promotes optimum dissemination and accessibility of scientific information generated within NBS and other agencies of the Federal government: promotes the development of the National Standard Reference Data System and a system of information analysis centers dealing with the broader aspects of the National Measurement System, and provides appropriate services to ensure that the NBS staff has optimum accessibility to the scientific information of the world. The Office consists of the following organizational units:

Office of Standard Reference Data-Clearinghouse for Federal Scientific and Technical Information :-Office of Technical Information and Publications-Library-Office of Public Information-Office of International Relations.

Headquarters and Laboratories at Gaithersburg. Maryland, unless otherwise noted; mailing address Washington, D.C. 20234. Located at Boulder, Colorado 80302.

3 Located at 5285 Port Royal Road Springfield Virginis 22151. 


\title{
A Selective Roll-to-Roll Printer for Producing Duplicate Microfilm Copies
}

\author{
James N. Strohlein and Thomas C. Bagg \\ Information Processing Technology Division \\ Center for Computer Sciences and Technology \\ National Bureau of Standards \\ Washington, D.C. 20234
}

NBS Technical Notes are designed to supplement the Bureau's regular publications program. They provide a means for making available scientific data that are of transient or limited interest. Technical Notes may be listed or referred to in the open literature. 

A Selective Roll-to-Roll Printer for Producing Duplicate Microfilm Copies*

"SELECTAFRAME" PRINTER

James N. Strohlein and Thomas C. Bagg

The "Selectaframe" printer, a convenient device for copying onto roll film selected frames from other rolls of film for subsequent automatic enlargement printing is described in detail.

Key words: Information retrieval device; microcopier; microfilm duplicator; reader-printer; selective copier

One widely used method to cope with the vast quantities of printed information is to microfilm originals and retain only the filmed copies. This has been commercially practiced for more than 40 years and many organizations have extensive film holdings in their libraries. Reference may be made to the information contained on these stored reels of film by viewing them on microfilm readers, and enlarged paper copies may be made if one uses a microfilm reader-printer. The latter is suitable to meet the needs of individuals who normally copy a small number of pages. However, for organizations which have large volume requirements for the selection and production of enlarged paper copies of references contained in their microfilm holdings, conventional reader-printers are not satisfactory. (Each print requires one cycle of operation usually requiring a fraction of a minute and as single sheets are used, the cost per sheet is high, depending on coating.)

The National Library of Medicine is developing a large file of microimages of deteriorating paper documents, in roll form. As part of its interlibrary loan and reference services enlargement prints are frequently required of selected articles from this file. The commercial copying devices available are designed to copy entire rolls to either film or paper. The conventional reader-printers are slow to operate, use costly paper and require great care to insure no damage to the master films. To overcome these difficulties,

* Work sponsored by the National Library of Medicine, Washington, D.C. 20514 
the National Bureau of Standards was asked to design and build a prototype "Selectaframe" printer as shown in figure 1. Basically it is a roll-to-roll printer specifically designed to generate duplicate frames on diazo film. As with conventional $35 \mathrm{~mm}$ roll film readers, the optics permit viewing the image on a large screen. The operator locates the desired frame in the usual manner either manually or by semi-automatic means such as using an odometer, electric frame counter, or such. When the desired frame is located, the operator presses the copy button which closes the gate to hold the original image film tightly to the copy film and activates the shutter for exposure. This film gate was designed to minimize the possibilities of scratching the film and yet obtain adequate contact pressure between the films for maximum information transfer. The film gate also contains a mask for adding a cut mark to each frame in the lower left hand corner. This cut mark permits automatic cutting of the enlargement prints. A single mercury lamp is used for both viewing and printing. The shutter is an ultraviolet filter which transmits only visible light to the projection system for viewing. During exposure the filter is flipped out of the optical path by a time controlled solenoid. For a typical diazo emulsion, the exposure time is about 3 seconds. After the exposure is completed and the shutter is closed, the film gate opens so the exposed diazo film can be automatically advanced for the next frame.

Upon completion of a series of exposures the exposed diazo film is removed from the printer and may then be developed in a diazo processor. Enlargement prints are made on an electrostatic roll-film printer and the pages cut and stacked automatically.

Figure 2 shows the completed machine in operation, with an image to be copied displayed on the screen. The operator's right hand is on the traversing lever, his left is near the "copy button". The cartridges shown were also fabricated at NBS by modifying $16 \mathrm{~mm}$ cartridges so that they would accept $35 \mathrm{~mm}$ film. On the panel to the left of the viewing screen is an alarm which signals depletion of the copy film supply, a counter which indicates the number of frames copied, and the main power "on-off" switch.

Figure 3 shows NBS instrument maker Charles Summers making an adjustment. This view, made with the upper housing (which contains the mirrors and viewing screen) removed shows the main components. The working master may be on conventional 100 foot reels or in $35 \mathrm{~mm}$ cartridges. The transparent copy $\mathrm{film}$ is shown feeding from the supply reel (which will accept 500 foot cored rolls) through the film 
gate to a conventional take-up reel driven by a modified microfilm camera film advance mechanism. The film gate consists of two optical flats which are held apart when the master film is moving for the selection scanning. If a frame is selected for copying, the flats are forced together by the cams which are actuated by a solenoid connected to the cable shown alongside the projection lens. In addition, there are adjustable masks in the gate to block out partial images of adjoining pages which appear due to the close spacing of images of small pages on the original film.

As the copy film is transparent, light for projection of the masterfilm image passes through both films for viewing on the screen. A single 400 watt high intensity mercury source is used. Since the diazo film is exposed with ultraviolet radiation, either movement of one of the films or the use of separate light sources is avoided by employing an ultraviolet filter which is interposed during the scanning mode (thus permitting only visible light to pass) and automatically retracted during the copy or exposure cycle. In Figure 3 the filter is shown in its retracted position between the film gate and the lamp housing, which contains a parabolic reflector and a quartz window supported by the lamp holders, all of which are enclosed in a shroud (not shown) to shield the light from the operator and to distribute the required cooling air. A bi-metal switch is provided to insure that the blowers remain on after the machine is turned off until the housing has cooled, and also a thermal fuse to turn the lamp off if the housing becomes excessively hot.

The master film is driven by a single motor with a clutch-brake linkage to the two reel shafts. Slow and fast, forward and reverse movement is controlled by a single toggle switch conveniently located on the base plate. The take-up reel drive is actuated as part of a cycle which is initiated by the operator when it is desired to copy a frame. The 'copy' push-button causes (I) the flats to press the two film emulsion surfaces together, (2) the U.V. filter to retract, (3) the initiation of a pre-set timer for the exposure length, (4) the film to advance one frame length upon completion of exposure.

Figure 4 shows the electrical circuits, covering the items described and also an alarm to signal depletion of the supply film, indicator lights to show cycle function and an auxiliary momentary contact switch to advance copy film without exposure when required for spacing runs or loading. 



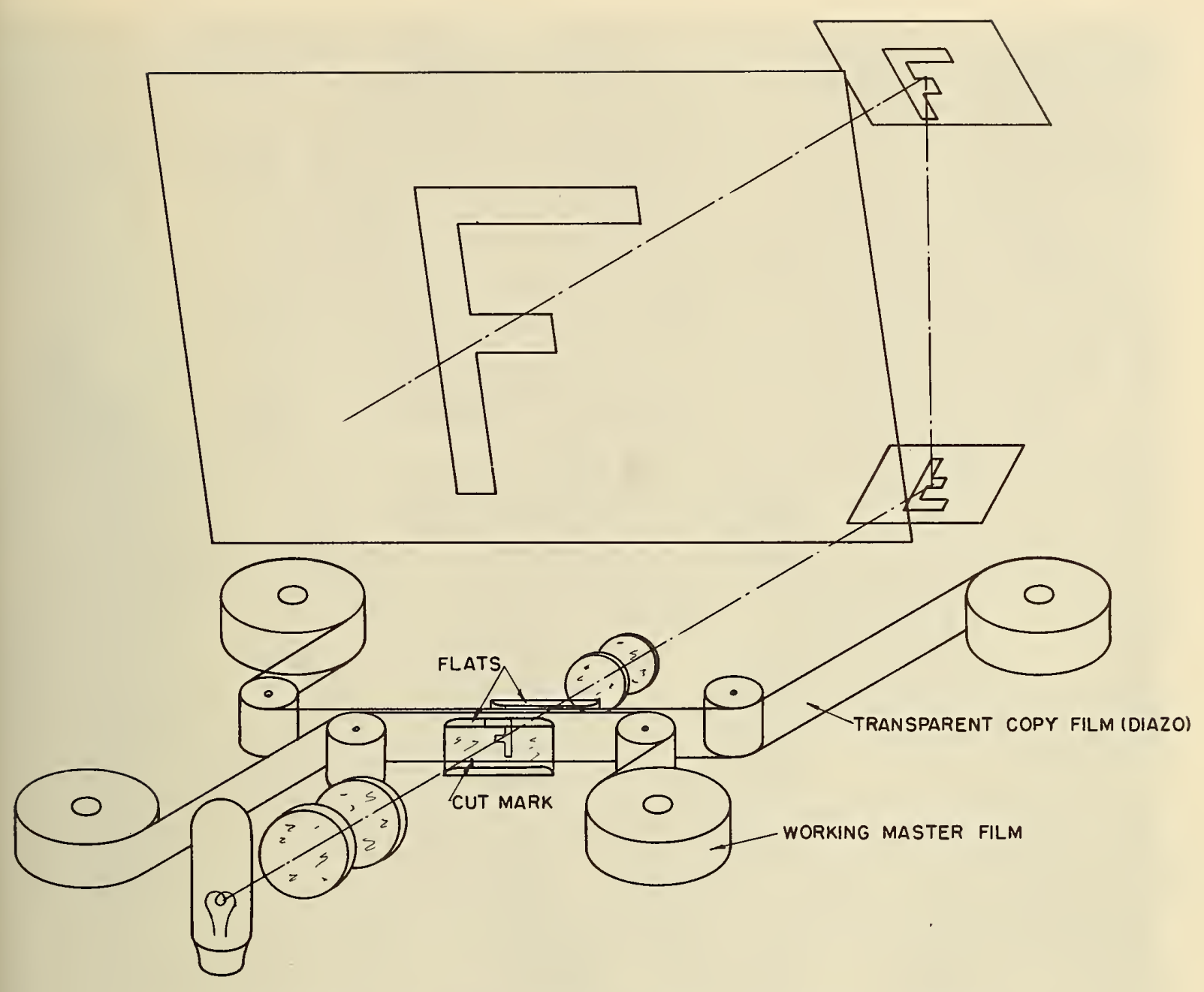

Figure 1. Basic scheme as proposed to NLM 


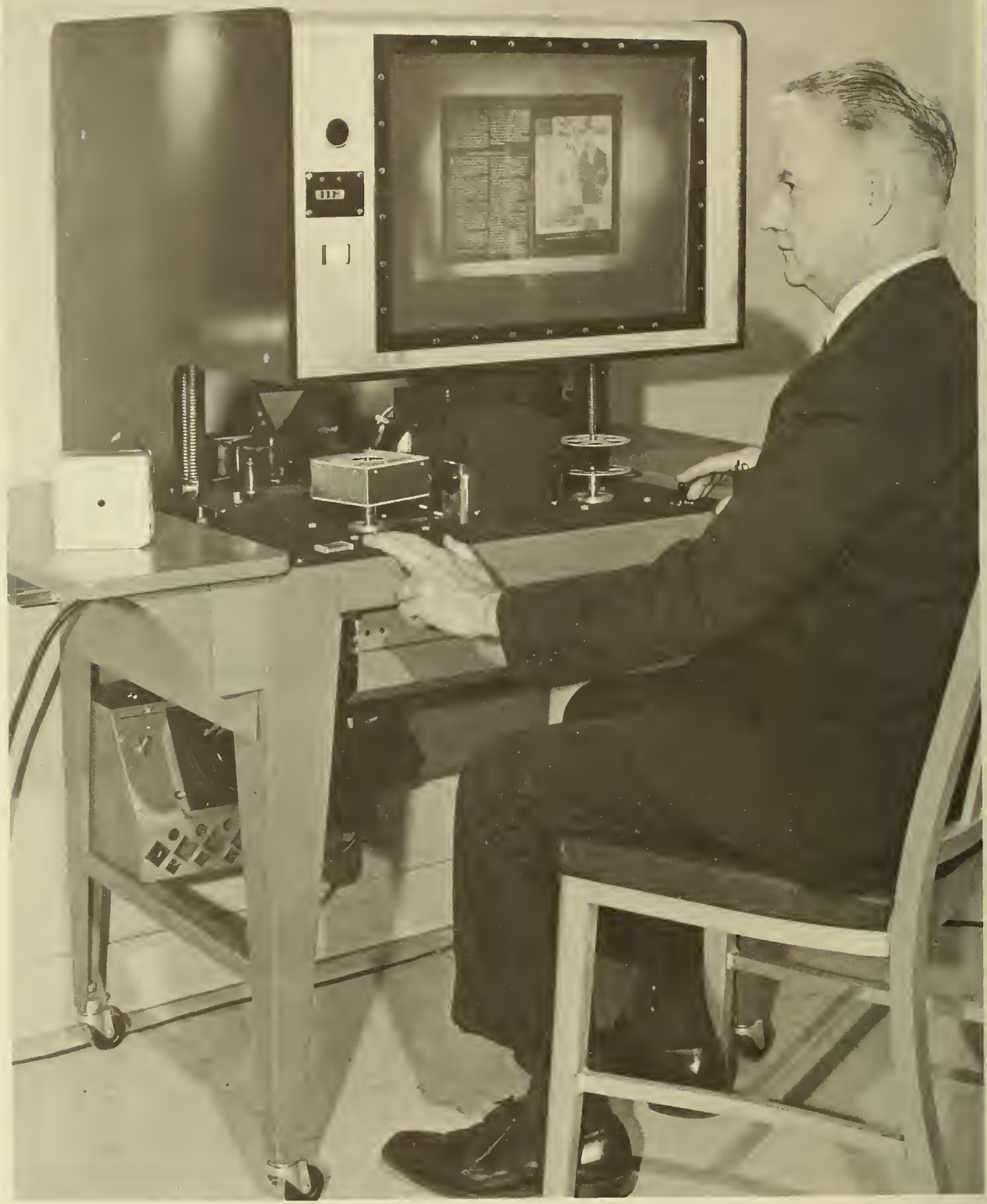

Figure 2. "SELECTAFRAME" in operation 


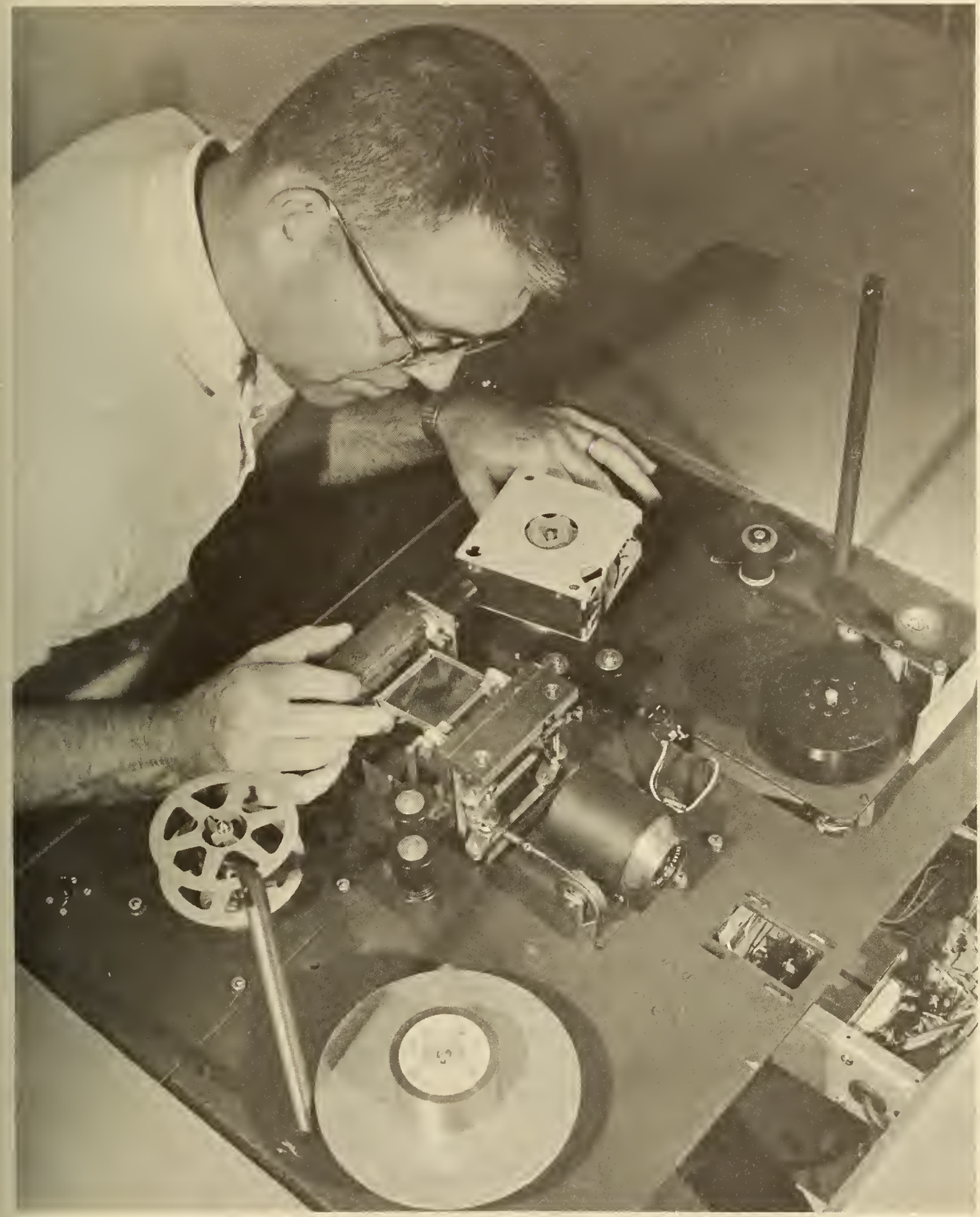

Figure 3. Main plate showing light source, filter-shutter, film gate, projection lens 


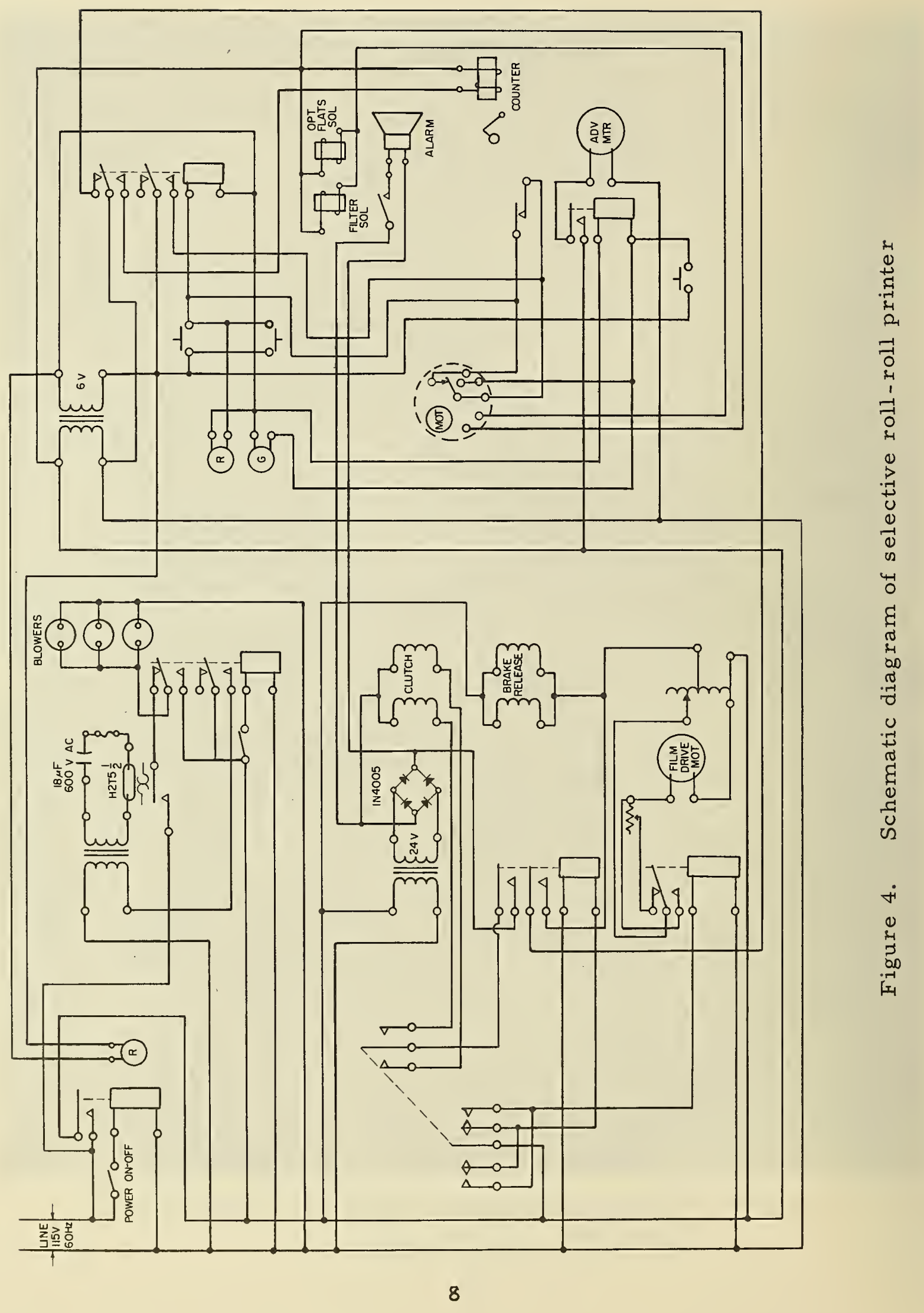




\section{THE NATIONAL ECONOMIC GOAL}

Sustained maximum growth in a free market economy, without inflation, under conditions of full employment and equal opportunity

\section{THE DEPARTMENT OF COMMERCE}

The historic mission of the Department is "to foster, promote and develop the foreign and domestic commerce" of the United States. This has evolved, as a result of legislative and administrative additions, to encompass broadly the responsibility to foster, serve and promote the nation's economic development and technological advancement. The Department seeks to fulfill this mission through these activities:

ricipating with ier government encies in the ation of national licy, through the ssident's Cabinet $d$ its subdivisions.

iabinet Committee in Economic Policy

Irban Affairs

;ouncil

invironmental

Luality Council
Promoting progressive Assisting states, business policies and communities and growth. individuals toward economic progress.

\section{- Business and} Defense Services Administration

\section{Office of Field} Services

\section{- Economic \\ Development \\ Administration}

- Regional Planning Commissions

- Office of Minority Business Enterpriso

TE: This schematic is neither an organization chart nor a gram outline for budget purposes. It is a general statement the Department's mission in relation to the national goal economic development.

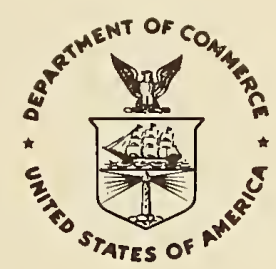

\section{MISSION AND}

FUNCTIONS

OF THE

DEPARTMENT OF COMMERCE

\author{
"to foster, serve and \\ promote the nation's \\ economic development \\ and technological \\ advancement"
}

Strengthening the international economic position of the United States.

\section{- Bureau of International \\ Commerce}

- Office of Foreign Commercial

Services

Office of Foreign Direct Investments

- United States Travel Service

- Maritime Administration
Assuring effective Acquiring, analyzing use and growth of the and disseminating nation's scientific information concernand technical resources.

- Environmental Science Services Administration

- Patent Office ing the nation and the economy to help achieve increased social and economic benefit.

- Bureau of the Census

- National Bureau of Standards

- Office of Business Economics
Office of

Telecommunications

- Office of State

Technical Services 



\section{PERIODICALS}

JOURNAL OF RESEARCH reports National Bureau of Standards research and development in physics, mathematics, chemistry, and engineering. Comprehensive scientific papers give complete details of the work, including laboratory data, experimental procedures, and theoretical and mathematical analyses. Illustrated with photographs, drawings, and charts.

Published in three sections, available separately:

\section{- Physics and Chemistry}

Papers of interest primarily to scientists working in these fields. This section covers a broad range of physical and chemical research, with major emphasis on standards of physical measurement, fundamental constants, and properties of matter. Issued six times a year. Annual subscription: Domestic, \$9.50; foreign, $\$ 11.75^{*}$.

\section{- Mathematical Sciences}

Studies and compilations designed mainly for the mathematician and theoretical physicist. Topics in mathematical statistics, theory of experiment design, numerical analysis, theoretical physics and chemistry, logical design and programming of computers and computer systems. Short numerical tables. Issued quarterly. Annual subscription: Domestic, $\$ 5.00$; foreign, $\$ 6.25^{*}$.

\section{- Engineering and Instrumentation}

Reporting results of interest chiefly to the engineer and the applied scientist. This section includes many of the new developments in instrumentation resulting from the Bureau's work in physical measurement, data processing, and development of test methods. It will also cover some of the work in acoustics, applied mechanics, building research, and cryogenic engineering. Issued quarterly. Annual subscription: Domestic, $\$ 5.00$; foreign, $\$ 6.25 *$.

\section{TECHNICAL NEWS BULLETIN}

The best single source of information concerning the Bureau's research, developmental, cooperative and publication activities, this monthly publication is designed for the industry-oriented individual whose daily work involves intimate contact with science and technology-for engineers, chemists, physicists, research managers, product-development managers, and company executives. Annual subscription: Domestic, $\$ 3.00$; foreign, $\$ 4.00^{*}$.

- Difference in price is due to extra cost of foreign mailine.

\section{NONPERIODICALS}

Applied Mathematics Series. Mathematical tables, manuals, and studies.

Building Science Series. Research results, test methods, and performance criteria of building materials, components, systems, and structures.

Handbooks. Recommended codes of engineering and industrial practice (including safety codes) developed in cooperation with interested industries, professional organizations, and regulatory bodies.

Special Publications. Proceedings of NBŚ conferences, bibliographies, annual reports, wall charts, pamphlets, etc.

Monographs. Major contributions to the technical literature on various subjects related to the Bureau's scientific and technical activities.

National Standard Reference Data Series. NSRDS provides quantitive data on the physical and chemical properties of materials, compiled from the world's literature and critically evaluated.

Product Standards. Provide requirements for sizes, types, quality and methods for testing various industrial products. These standards are developed cooperatively with interested Government and industry groups and provide the basis for common understanding of product characteristics for both buyers and sellers. Their use is voluntary.

Technical Notes. This series consists of communications and reports (covering both other agency and NBS-sponsored work) of limited or transitory interest.

Federal Information Processing Standards Publications. This series is the official publication within the Federal Government for information on standards adopted and promulgated under the Public Law 89-306, and Bureau of the Budget Circular A-86 entitled, Standardization of Data Elements and Codes in Data Systems.

\section{CLEARINGHOUSE}

The Clearinghouse for Federal Scientific and Technical Information, operated by NBS, supplies unclassified information related to Government-generated science and technology in defense, space, atomic energy, and other national programs. For further information on Clearinghouse services, write:

Clearinghouse

U.S. Department of Commerce

Springfield, Virginia 22151 
U.S. DEPARTMENT OF COMMERCE

WASHINGTON, D.C. 20230

OFFICIAL BUSINESS

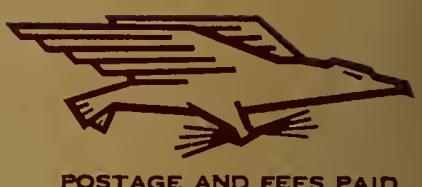

U.S. DEPARTMENT OF COMMERCE 